\title{
Influence of Dissolved Organic Matter and Fe(II) on the Abiotic Reduction of Pentachloronitrobenzene
}

\author{
J. Alexandra Hakala ${ }^{1}$, Yu-Ping Chin ${ }^{1 *}$, Eric J. Weber ${ }^{2}$ \\ ${ }^{1}$ School of Earth Sciences, The Ohio State University, Columbus, Ohio, 43210, ${ }^{2}$ Ecosystems \\ Research Division, United States Environmental Protection Agency, Athens, Georgia, 30605
}

Environmental Science and Technology

Revised Version: August 2, 2007

Original Submission: March 14, 2007

Supporting Information

Pages: 12

Figures: 6

Tables: 1 


\section{Description of Methods Referred to in Main Text}

\section{HPLC Analysis Methods}

The analytes and derivatives of PCNB reduction were assayed by HPLC using either a Waters 1525 binary HPLC pump, 2487 dual $\lambda$ absorbance detector with a 717 Plus autosampler or a Shimadzu SCL-10AT pump, SIL-10A autosampler, DGU-14A degasser, SCL-10A system controller, and SPD-10A UV/Vis detector. All compounds were detected at a wavelength of 225 nm. Samples were injected in volumes of 200 to $250 \mu \mathrm{L}$ and analytes were separated through a reverse-phase $\mathrm{C}_{18}$ column (a Waters Nova-Pak $\mathrm{C}_{18}, 3.9$ x $150 \mathrm{~mm}$ or a Restek Pinnacle II $\mathrm{C}_{18}, 5$ $\mu \mathrm{m}, 150 \times 4.6 \mathrm{~mm}$ ) using either an 80/20,77/23, or 75/25 methanol/water mobile phase acidified to $\mathrm{pH} 2.8$ to 3.6 with concentrated $\mathrm{HCl}$. Concentrations of PCNB and PCA were calculated by comparison with calibration standards of known concentration. Kinetic parameters were determined by a least squares fitting of the concentration-versus-time data with the fitting program MicroMath Scientist and the regression wizard function in SigmaPlot 10.0.

\section{Fe(II) Measurements}

Aliquots $(\sim 2 \mathrm{~mL})$ for $\mathrm{Fe}(\mathrm{II})$ measurements were taken from each reaction premixture (prior to reaction with PCNB) and acidified with 20 to $30 \mu \mathrm{L} 2 \mathrm{~N} \mathrm{HCl}$. Each aliquot was filtered with a Milli-Q-rinsed 0.2- $\mu \mathrm{m}$ filter (Acrodisc $13 \mathrm{~mm}$ syringe filter with HT Tuffryn membrane) and $1 \mathrm{~mL}$ of the $0.2-\mu \mathrm{m}$-filtered aliquot was reacted with $1.0 \mathrm{~mL}$ of an aqueous 1,10 phenanthroline solution $(\sim 5.4 \mathrm{mM}), 0.5 \mathrm{~mL}$ ammonium acetate buffer $(\sim 3.8 \mathrm{M})$ and $2.5 \mathrm{~mL}$ Milli-Q water. In some cases the aliquot was filtered with a $0.45-\mu \mathrm{m}$ filter, and [Fe(II)] measured for the $0.2-\mu \mathrm{m}$-filtered and $0.45-\mu \mathrm{m}$-filtered aliquots were within $5 \%$. The $\mathrm{Fe}(\mathrm{II})-1,10-$ phenanthroline complex absorbance was measured in plastic cuvettes at a wavelength of $508 \mathrm{~nm}$ (either with a Varian Cary 1 or Shimadzu UV-1201 UV/Vis spectrophotometer) zeroed to a 
$\mathrm{Fe}(\mathrm{II})$-free blank containing the colorimetric reagents. Concentration was calculated from a linear equation relating absorbance to calibration standard concentrations (range of 10 to 1000 $\mu \mathrm{M} \mathrm{Fe}(\mathrm{II}))$.

\section{Filter-sterilized Microbial Control Reactions}

Filter-sterilized control experiments were performed with a solution containing Fe(II) and PLFA, and a PLFA-only solution. Solutions were prepared and filtered with a $0.45-\mu \mathrm{m}$-filter in the same manner as the $0.45-\mu \mathrm{m}$-filtered experiments, and sterilized by further filtration through a sterile $0.2-\mu \mathrm{m}$ filter ( $25 \mathrm{~mm}$ diameter, Pall Acrodisc) into autoclaved syringes.

\section{Kinetic Models}

PCNB reduction to PCA was modeled using both pseudo-zero-order and pseudo-first-order kinetic models. The pseudo-zero-order rate constant is represented by $k_{A Z}$ (Eqn 1 ).

$$
[\mathrm{PCNB}]=[\mathrm{PCNB}]_{0}-k_{A Z} t
$$

The pseudo first-order rate constant is represented by $k_{A}$ (Eqn 2).

$$
[\mathrm{PCNB}]=[\mathrm{PCNB}]_{0} e^{-k_{A} t}
$$

In Eqs 1 and 2, $t$ represents reaction time and $[\mathrm{PCNB}]_{0}$ represents the initial concentration of $\mathrm{PCNB}$. The value for $[\mathrm{PCNB}]_{0}$ was determined as a parameter during each model fit because the true initial reactant concentration could not be measured due to its immediate reduction upon addition to the reaction medium. Determination of whether a reaction proceeded via pseudozero- or pseudo-first-order kinetics was made by a comparison of statistical data for the least squares fits. However, it is often difficult to identify the accuracy of a particular model when fitting the measured data points. This observation is partially due to the limits inherent in small data sets, and to the fact that both models are simplified explanations of complex reaction dynamics. All kinetic modeling performed in this study, and the rate constants obtained from 
these kinetic models, are only valid for situations in which $[\mathrm{PCNB}] \sim 1 \mu \mathrm{M}$ under the conditions reported here.

We observed the appearance of a reactive intermediate in the Fe(II)-only system that was absent in the $\mathrm{Fe}(\mathrm{II})-\mathrm{DOM}$ experiments (Figure 6). Extended discussion on this matter is presented in the main text. Thus, only the loss of PCNB was modeled in the kinetics studies. Formation of PCA was monitored to ensure that the reaction proceeded to completion ([PCA $]_{\text {final }}$ $\approx[\mathrm{PCNB}]_{0}$ ) and that PCNB was not lost through volatilization from or sorption to the HPLC autosampler vials.

\section{Influence of Aged DOM Stock Solutions}

In the Fe(II)-PLFA $0.45-\mu$ m-filtered reactions, we only observed fast PCNB reduction in solutions prepared with freshly-made fulvic acid stock solutions (made within 2 months of performing the reaction). Reactions performed under $0.45-\mu \mathrm{m}$-filtered conditions at $\mathrm{pH} \approx 7.8$, $[\mathrm{Fe}(\mathrm{II})] \approx 850 \mu \mathrm{M}$ and $[\mathrm{DOC}] \approx 1 \mathrm{mM}-\mathrm{C}$ with 6-month-old PLFA solutions (stored at $4^{\circ} \mathrm{C}$ ) showed mixed pseudo-zero-order and pseudo-first-order kinetics that were roughly as fast $\left([\mathrm{PCNB}]=0.5[\mathrm{PCNB}]_{0}\right.$ at $\left.\approx 100 \mathrm{~min}\right)$ as the fastest reactions observed in anoxic $\mathrm{Fe}(\mathrm{II})$-only systems $\left([\mathrm{PCNB}]=0.5[\mathrm{PCNB}]_{0}\right.$ at $\approx 90 \mathrm{~min} ;$ Table S1). In contrast, $0.45-\mu \mathrm{m}$-filtered Fe(II)PLFA reactions performed under the same $\mathrm{pH}, \mathrm{Fe}(\mathrm{II})$ and $\mathrm{DOC}$ conditions with freshly made PLFA solution (prepared with Milli-Q and the PLFA XAD-8 isolate 3 days prior to performing the reaction), were very fast $\left([\mathrm{PCNB}]=0.5[\mathrm{PCNB}]_{0}\right.$ at $\approx 20$ minutes $)$. This occurrence was only observed in $0.45-\mu \mathrm{m}$-filtered Fe(II)-PLFA systems. In contrast PCNB reduction in aged (6 months stored at $\left.4^{\circ} \mathrm{C}\right) 0.45$ - $\mu \mathrm{m}$-filtered $\mathrm{Fe}(\mathrm{II})$-SRFA reactions at $\mathrm{pH} \approx 7.8,[\mathrm{Fe}(\mathrm{II})] \approx 850 \mu \mathrm{M}$ and $[\mathrm{DOC}] \approx 1 \mathrm{mM}-\mathrm{C}$ proceeded as quickly as freshly prepared $0.45-\mu \mathrm{m}$-filtered $\mathrm{Fe}(\mathrm{II})$-DOM 
reactions. These results show that the PCNB reduction rate in $\mathrm{Fe}(\mathrm{II})-\mathrm{DOM}$ systems can slow in some cases by an aged stock solution (the PLFA in our study).

\section{$\underline{\text { Rate Constants for } 0.45-\mu m-\text { filtered Reactions }}$}

Table S1. Table of rate constants for reactions performed in $0.45-\mathrm{mm}$-filtered Fe(II)-only,

Fe(II)-PLFA and Fe(II)-SRFA reactions. Reaction conditions are listed for each reaction.

\begin{tabular}{|c|c|c|c|c|c|c|}
\hline Reaction & $\begin{array}{c}\text { Reaction } \\
\text { Order }\end{array}$ & $\begin{array}{c}k_{A}\left(\min ^{-1}\right) \text { or } k_{A Z}(\mu M \\
\left.\min ^{-1}\right)\left(\times 10^{-2}\right)\end{array}$ & $\begin{array}{c}\operatorname{Error}^{\mathrm{a}}\left(\mathrm{min}^{-1} \text { or }\right. \\
\left.\mu \mathrm{M} \mathrm{min}^{-1}\right)\end{array}$ & pH & {$[\mathrm{Fe}(\mathrm{II})]^{\mathrm{b}}(\mu \mathrm{M})$} & [DOC] $(\mathrm{mM}-\mathrm{C})$ \\
\hline $\mathrm{Fe}(\mathrm{II})$-only & 0 & 0.10 & 0.01 & 7.61 & 460 & 0 \\
\hline $\mathrm{Fe}(\mathrm{II})$-only & 0 & 0.22 & 0.02 & 7.78 & 910 & 0 \\
\hline $\mathrm{Fe}(\mathrm{II})$-only & 0 & 0.24 & 0.04 & 7.78 & 930 & 0 \\
\hline $\mathrm{Fe}(\mathrm{II})$-only & 0 & 0.41 & 0.02 & 7.79 & 880 & 0 \\
\hline $\mathrm{Fe}(\mathrm{II})$-only & 1 & 0.35 & 0.04 & 7.77 & 480 & 0 \\
\hline $\mathrm{Fe}(\mathrm{II})$-only & 1 & 0.76 & 0.16 & 7.78 & 900 & 0 \\
\hline $\mathrm{Fe}(\mathrm{II})$-only & 1 & 0.30 & 0.04 & 7.79 & 340 & 0 \\
\hline $\mathrm{Fe}(\mathrm{II}) \mathrm{SRFA}$ & 1 & 0.50 & 0.07 & 7.76 & 430 & 1.44 \\
\hline $\mathrm{Fe}(\mathrm{II}) \mathrm{SRFA}$ & 1 & 1.03 & 0.08 & 7.80 & 840 & 1.26 \\
\hline $\mathrm{Fe}(\mathrm{II}) \mathrm{SRFA}$ & 1 & 1.33 & 0.10 & 7.80 & 850 & 1.26 \\
\hline $\mathrm{Fe}(\mathrm{II}) \mathrm{SRFA}$ & 1 & 1.16 & 0.10 & 7.80 & 860 & 1.26 \\
\hline $\mathrm{Fe}(\mathrm{II}) \mathrm{SRFA}$ & 1 & 0.32 & 0.04 & 7.82 & 230 & 1.27 \\
\hline $\mathrm{Fe}(\mathrm{II}) \mathrm{SRFA}$ & 1 & 1.27 & 0.08 & 7.82 & 590 & 1.27 \\
\hline $\mathrm{Fe}(\mathrm{II}) \mathrm{PLFA} \mathrm{A}^{\mathrm{c}}$ & 0 & 0.34 & 0.16 & 7.77 & 840 & 1.20 \\
\hline $\mathrm{Fe}(\mathrm{II}) \mathrm{PLFA}$ & 1 & 0.66 & 0.08 & 7.77 & 850 & 1.20 \\
\hline $\mathrm{Fe}(\mathrm{II}) \mathrm{PLFA}^{\mathrm{c}}$ & 1 & 0.44 & 0.23 & 7.77 & 840 & 1.20 \\
\hline $\mathrm{Fe}(\mathrm{II}) \mathrm{PLFA}^{\mathrm{d}}$ & 1 & 3.24 & 0.29 & 7.78 & 880 & 0.84 \\
\hline $\mathrm{Fe}(\mathrm{II}) \mathrm{PLFA}^{\mathrm{d}}$ & 1 & 3.46 & 0.27 & 7.78 & 880 & 0.84 \\
\hline $\mathrm{Fe}(\mathrm{II}) \mathrm{PLFA}^{\mathrm{d}}$ & 1 & 3.46 & 0.39 & 7.78 & 890 & 0.84 \\
\hline $\mathrm{Fe}(\mathrm{II}) \mathrm{PLFA}^{\mathrm{d}}$ & 1 & 0.38 & 0.04 & 7.82 & 220 & 1.28 \\
\hline $\mathrm{Fe}(\mathrm{II}) \mathrm{PLFA}^{\mathrm{d}}$ & 1 & 0.52 & 0.12 & 7.85 & 600 & 1.28 \\
\hline $\mathrm{Fe}(\mathrm{II}) \mathrm{PLFA}^{\mathrm{d}}$ & $1^{\mathrm{e}}$ & 0.81 & 0.10 & 7.83 & 780 & 1.28 \\
\hline $\mathrm{Fe}(\mathrm{II}) \mathrm{PLFA}^{f}$ & $1^{\mathrm{e}}$ & 0.39 & 0.06 & 7.80 & 710 & 1.28 \\
\hline
\end{tabular}

${ }^{\mathrm{a}}$ Rate constant error reported as one half of the $95 \%$ confidence interval for the kinetic fit.

${ }^{\mathrm{b}}$ Concentrations represent values for the $0.45-\mu \mathrm{M}$ fraction of the reaction media. ${ }^{\mathrm{c}}$ Reactions performed with 6-month-old PLFA stock solution. ${ }^{\mathrm{d}}$ Reactions performed with 3-day-old PLFA stock solution. ${ }^{\mathrm{e}}$ Reactions only performed to one half-life; pseudo-first-order kinetics are assumed. ${ }^{\mathrm{f}}$ Reactions performed with week-old PLFA stock under filter-sterilized conditions. 
Reduction Reactions Observed in Unfiltered Systems Containing Fe(II)

Kinetic data and PCS measurements were collected for unfiltered reactions in Fe(II)-only (Figure S1A), Fe(II)-SRFA (Figure S1B) and Fe(II)-PLFA (Figure S1C) reaction media.

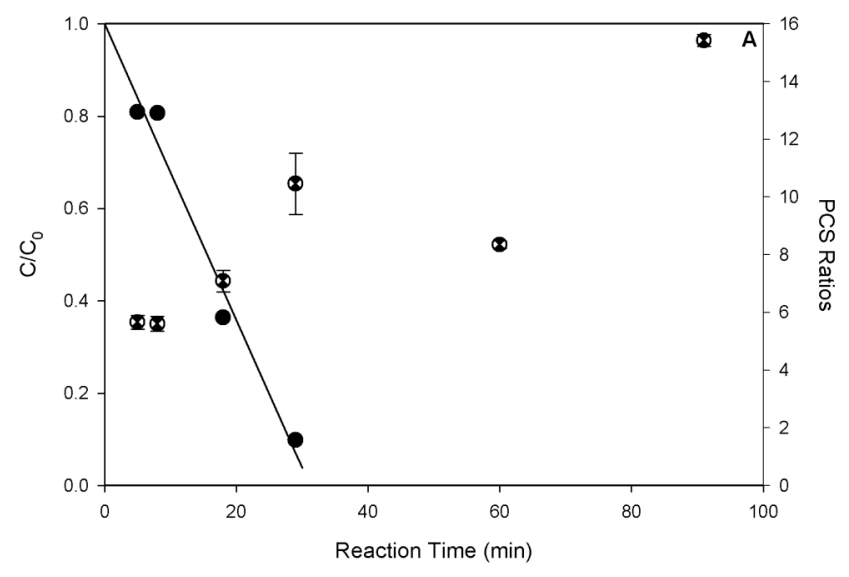

- $\mathrm{Fe}(\mathrm{II})$-only PCNB

- Fe(II)-only $0^{\text {th }}$ Order Fit

- $\mathrm{Fe}(\mathrm{II})$-only PCS Ratio

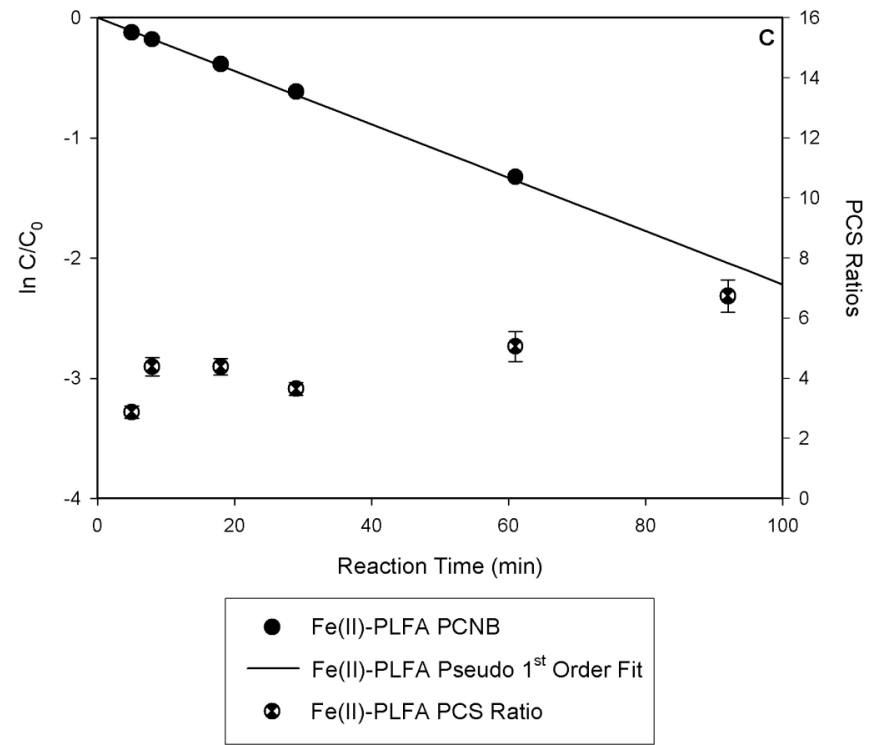

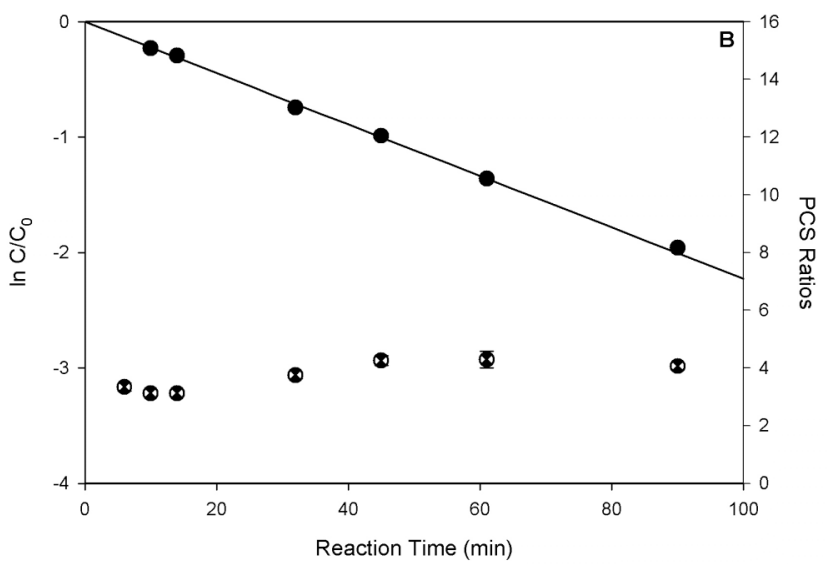

- $\mathrm{Fe}(I I)-S R F A$ PCNB

- Fe(II)-SRFA $1^{\text {st }}$ Order Fit

- Fe(II)-SRFA PCS Ratio

Figure S1. PCNB reduction in unfiltered Fe(II)-only and Fe(II)-DOM systems. A) Fe(II)-only at $\mathrm{pH} 7.62,[\mathrm{Fe}(\mathrm{II})]_{\mathrm{aq}}=460 \mu \mathrm{M}$ and observed PCS ratios (ratio to estimated blank values), with 
pseudo-zero-order kinetics, $k_{A Z}=2.73 \pm 1.33 \times 10^{-2} \mu \mathrm{M} \mathrm{\operatorname {min } ^ { - 1 }}$. B) Fe(II)-SRFA system at $\mathrm{pH}$ 7.82, $[\mathrm{Fe}(\mathrm{II})]_{\mathrm{aq}}=800 \mu \mathrm{M},[\mathrm{SRFA}]=1.8 \mathrm{mM}-\mathrm{C}$, and observed PCS ratios (ratio to SRFA-MOPS solution without $\mathrm{Fe}(\mathrm{II})$ ), with pseudo-first-order kinetics, $k_{A}=2.23 \pm 0.15 \times 10^{-2} \mathrm{~min}^{-1}$. C) $\mathrm{Fe}(\mathrm{II})-\mathrm{PLFA}$ system at $\mathrm{pH} 7.79,[\mathrm{Fe}(\mathrm{II})]_{\mathrm{aq}}=430 \mu \mathrm{M},[\mathrm{PLFA}]=1.7 \mathrm{mM}-\mathrm{C}$ and observed PCS ratios (ratio to PLFA-MOPS solution without Fe(II)), with pseudo-first-order kinetics, $k_{A}=2.22$ $\pm 0.26 \times 10^{-2} \mathrm{~min}^{-1}$. Rate constant error is reported at the $95 \%$ confidence interval. Data for the Fe(II)-SRFA reaction presented (Figure S1B) are from a different reaction set than the Fe(II)only and Fe(II)-PLFA reactions (Figures S1A and S1C, respectively). 


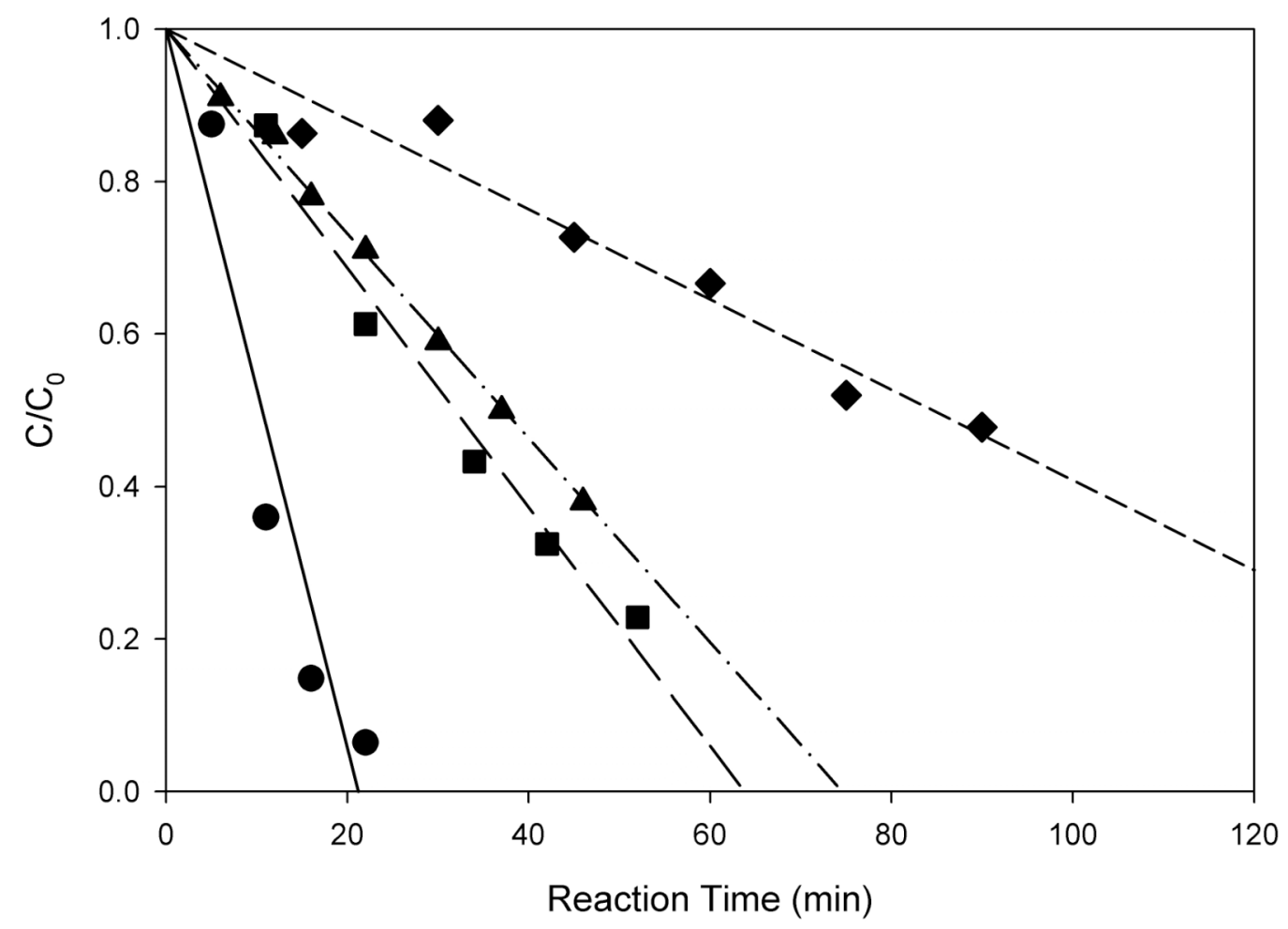

\begin{tabular}{|c|c|}
\hline$+\mathrm{C}$ & $\begin{array}{l}\text { Observed PCNB for }[\mathrm{Fe}(\mathrm{II})]=530 \mu \mathrm{M}, \mathrm{pH}=7.66 \\
\text { Pseudo- } 0^{\text {th }} \text {-order } \mathrm{k}_{\mathrm{AZ}}=3.50 \pm 3.89 \times 10^{-2} \mu \mathrm{M} \mathrm{min}{ }^{-1} \mathrm{~A}\end{array}$ \\
\hline$\underline{-1}$ & $\begin{array}{l}\text { Observed PCNB for }[\mathrm{Fe}(\mathrm{II})]=390 \mu \mathrm{M}, \mathrm{pH}=7.76 \\
--\quad \text { Pseudo- } 0^{\text {th }} \text {-order } \mathrm{k}_{\mathrm{AZ}}=1.30 \pm 0.41 \times 10^{-2} \mu \mathrm{M} \mathrm{min}^{-1}\end{array}$ \\
\hline$\Delta$ & $\begin{array}{l}\text { Observed PCNB for }[\mathrm{Fe}(\mathrm{II})]=870 \mu \mathrm{M}, \mathrm{pH}=7.75 \\
-\quad \text { Pseudo- } 0^{\text {th }} \text {-order } \mathrm{k}_{\mathrm{AZ}}=1.09 \pm 0.05 \times 10^{-2} \mu \mathrm{M} \mathrm{min}{ }^{-1}\end{array}$ \\
\hline$-C$ & $\begin{array}{l}\text { Observed PCNB for }[\mathrm{Fe}(\mathrm{II})]=70 \mu \mathrm{M}, \mathrm{pH}=7.73 \\
\quad \text { Pseudo-0 } 0^{\text {th }} \text {-order } \mathrm{k}_{\mathrm{AZ}}=0.47 \pm 0.15 \times 10^{-2} \mu \mathrm{M} \mathrm{min}^{-1}\end{array}$ \\
\hline
\end{tabular}

Figure S2. Pseudo-zero-order kinetic fits for PCNB reduction in unfiltered Fe(II)-only systems. The pseudo-first-order fits for these reactions are shown in Figure 2 of the main text. Error is reported as one half of the $95 \%$ confidence interval for the rate constant. ${ }^{A}$ Error of the pseudo-zero-order fit results in a negative value for these kinetic points. 


\section{$\underline{0.45-\mu m-f i l t e r e d ~ S y s t e m s ~ F i l t e r-s t e r i l i z e d ~ a n d ~ P s e u d o-f i r s t-o r d e r ~ D a t a ~}$}

Filter-sterilized Fe(II)-PLFA systems showed no significant difference in reactivity compared to non-sterile $0.45-\mu \mathrm{m}$-filtered reactions (Figure S3). In addition to the Fe(II)-PLFA filter-sterilized experiments, experiments with PLFA-only systems were conducted to compare reduction under non-sterile $0.45-\mu \mathrm{m}$-filtered and $0.2-\mu \mathrm{m}$-filter-sterilized systems. No major difference between the two reaction systems was observed.
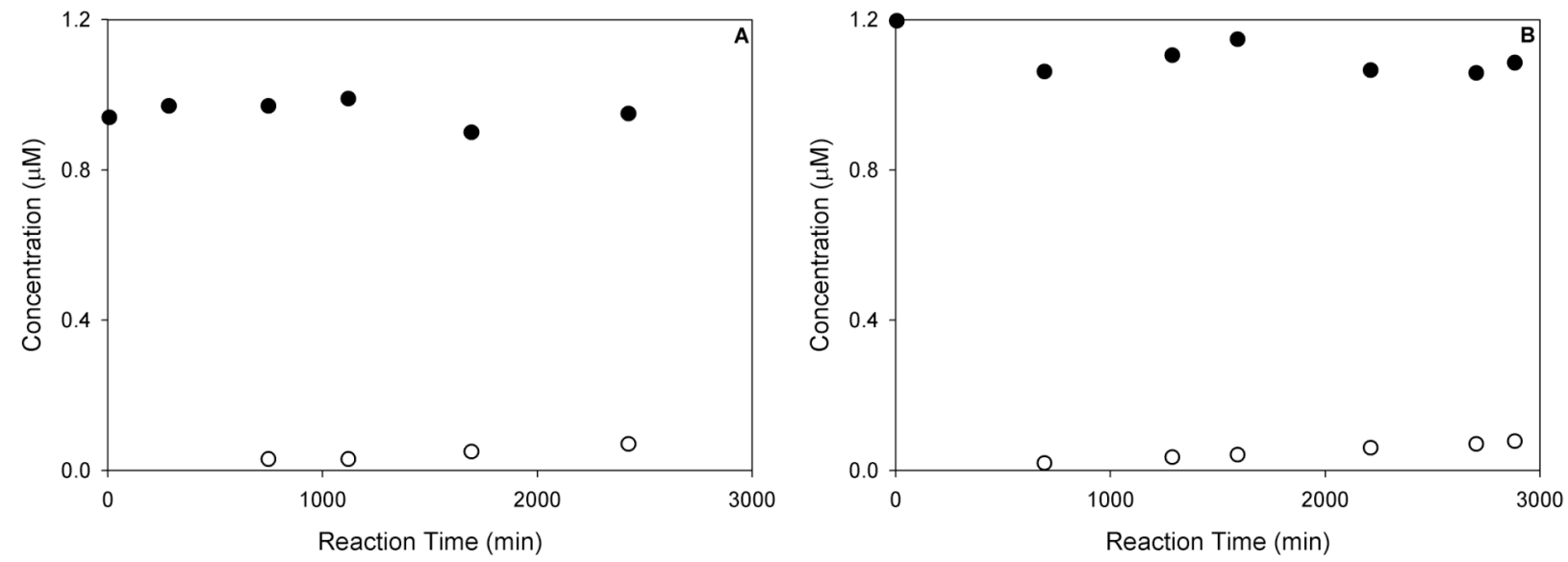

Figure S3. PCNB reduction in A) non-sterile $0.45-\mu \mathrm{m}$-filtered systems and B) $0.2-\mu \mathrm{m}$-filtersterilized systems. [DOC] $=1.28 \mathrm{mM}-\mathrm{C}$ and $\mathrm{pH}=7.80 \pm 0.04$ for the reactions. At $1642 \pm 51$ $\min (27.4 \pm 0.9 \mathrm{~h}),[\mathrm{PCA}]=0.05 \mu \mathrm{M}$ for the non-sterile reaction $(\mathrm{A})$ and $[\mathrm{PCA}]=0.04 \mu \mathrm{M}$ for the sterile reaction $(\mathrm{B})$. 


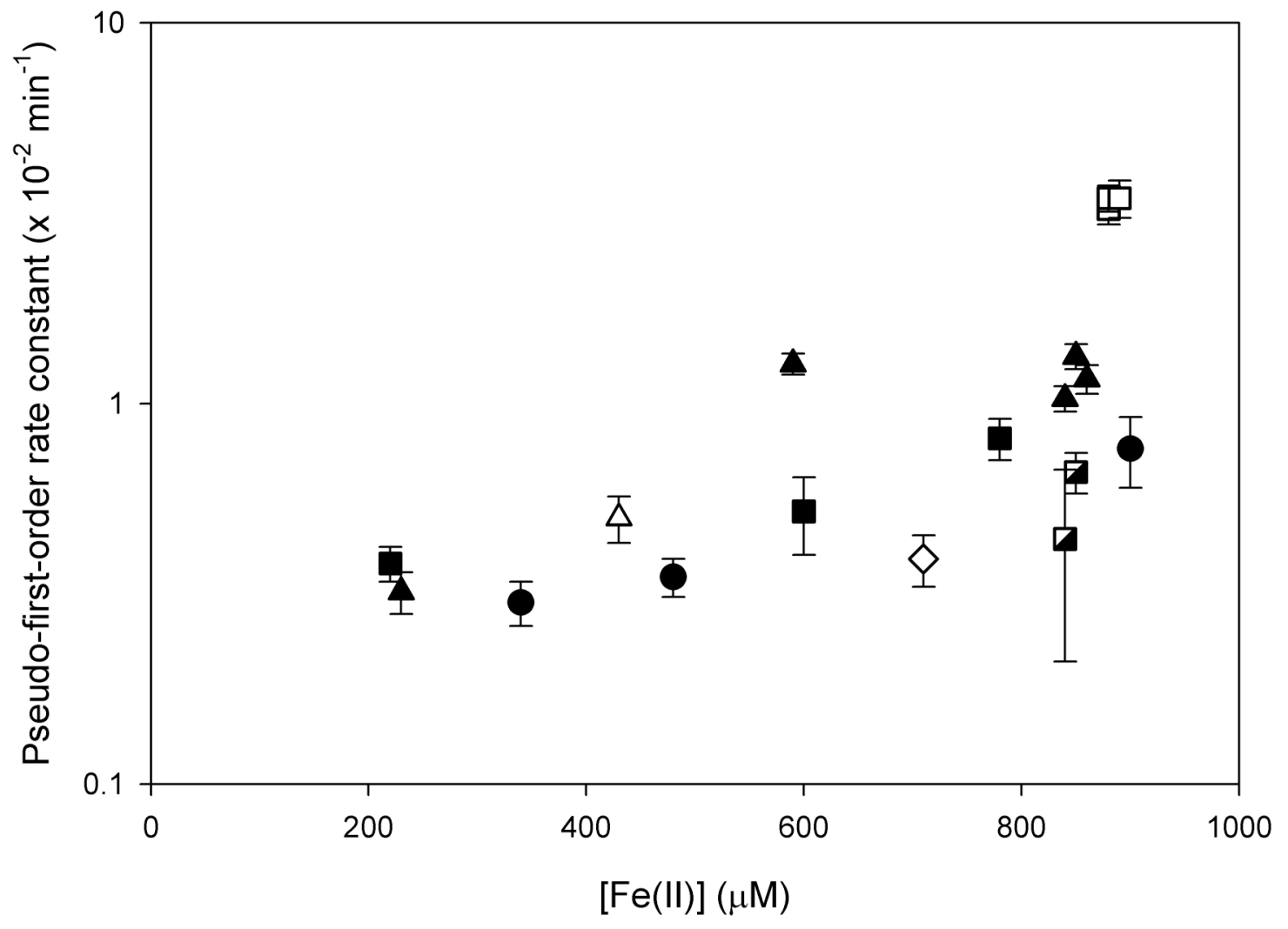

\begin{tabular}{|ll|}
\hline & Fe(II)-only \\
$\square$ & $\mathrm{Fe}(\mathrm{II})-\mathrm{PLFA},[\mathrm{DOC}]=0.84 \mathrm{mM}-\mathrm{C}$ \\
$\square$ & $\mathrm{Fe}(\mathrm{II})-\mathrm{PLFA},[\mathrm{DOC}]=1.20 \mathrm{mM}-\mathrm{C}$ (aged PLFA stock) \\
$\square$ & $\mathrm{Fe}(\mathrm{II})-\mathrm{PLFA},[\mathrm{DOC}]=1.28 \mathrm{mM}-\mathrm{C}$ \\
$\diamond$ & $\mathrm{Fe}(\mathrm{II})-\mathrm{PLFA},[\mathrm{DOC}]=1.28 \mathrm{mM}-\mathrm{C}$ (filter-sterilized control) \\
$\triangle$ & $\mathrm{Fe}(\mathrm{II})-\mathrm{SRFA},[\mathrm{DOC}]=1.44 \mathrm{mM}-\mathrm{C}$ \\
$\mathbf{\Delta}$ & $\mathrm{Fe}(\mathrm{II})-\mathrm{SRFA},[\mathrm{DOC}]=1.27 \pm 0.01 \mathrm{mM}-\mathrm{C}$ \\
\hline
\end{tabular}

Figure S4. Pseudo-first-order rate constants versus $[\mathrm{Fe}(\mathrm{II})](0.45-\mu \mathrm{m}$ fraction) for reactions performed in 0.45- $\mu \mathrm{m}$-filtered Fe(II)-only, Fe(II)-PLFA and Fe(II)-SRFA systems at pH $7.80 \pm$ 0.05. Rate constants and specific reaction conditions are listed in Table S1. 
Unfiltered Systems Pseudo-first-order Data

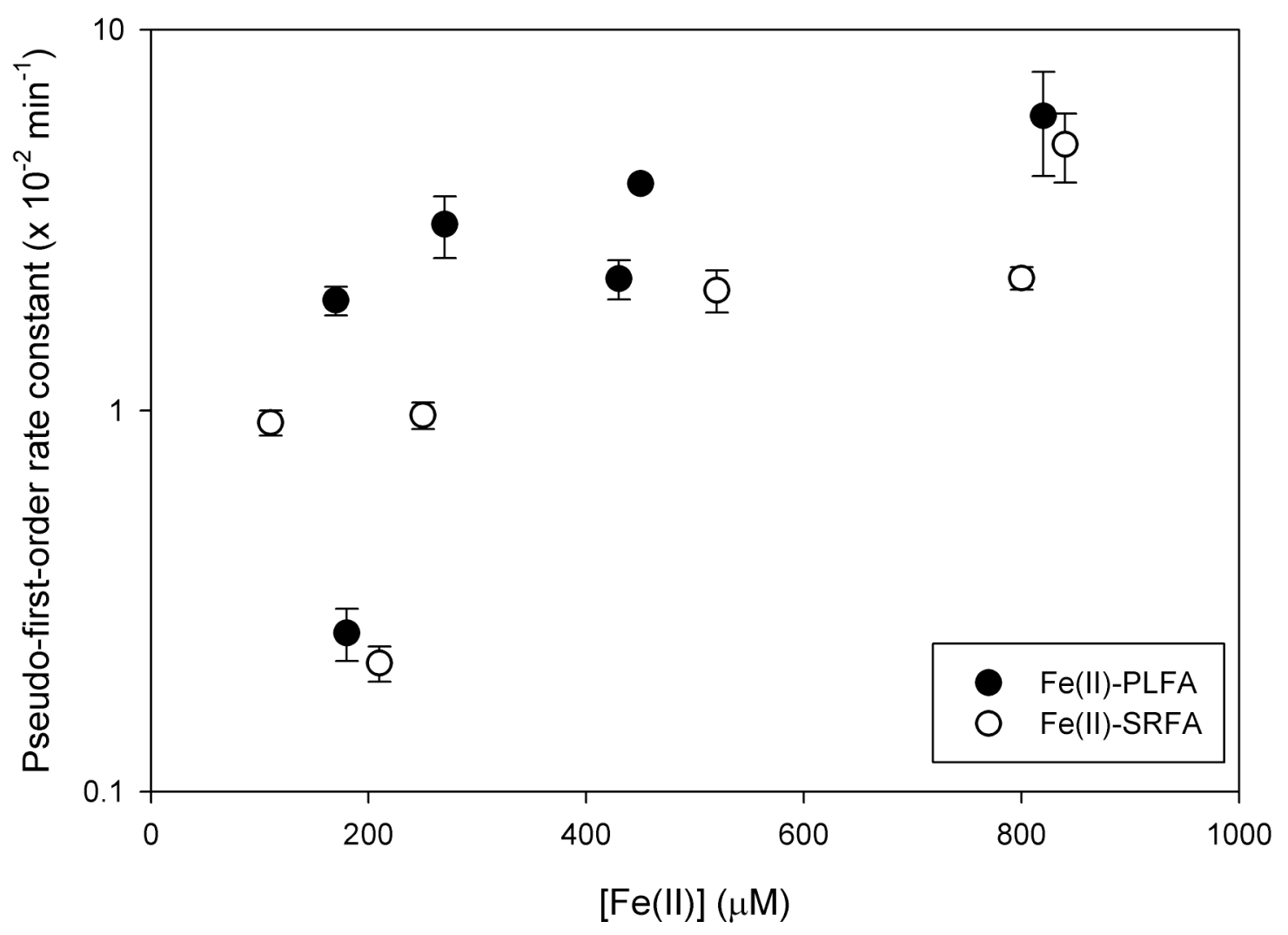

Figure S5. Pseudo-first-order rate constants versus [Fe(II)] $(0.2-\mu \mathrm{m}$ fraction) for reactions performed in unfiltered Fe(II)-PLFA and Fe(II)-SRFA systems at $\mathrm{pH} 7.73 \pm 0.11$. 
$\underline{\text { Kinetic Plot of Reaction Intermediates }}$

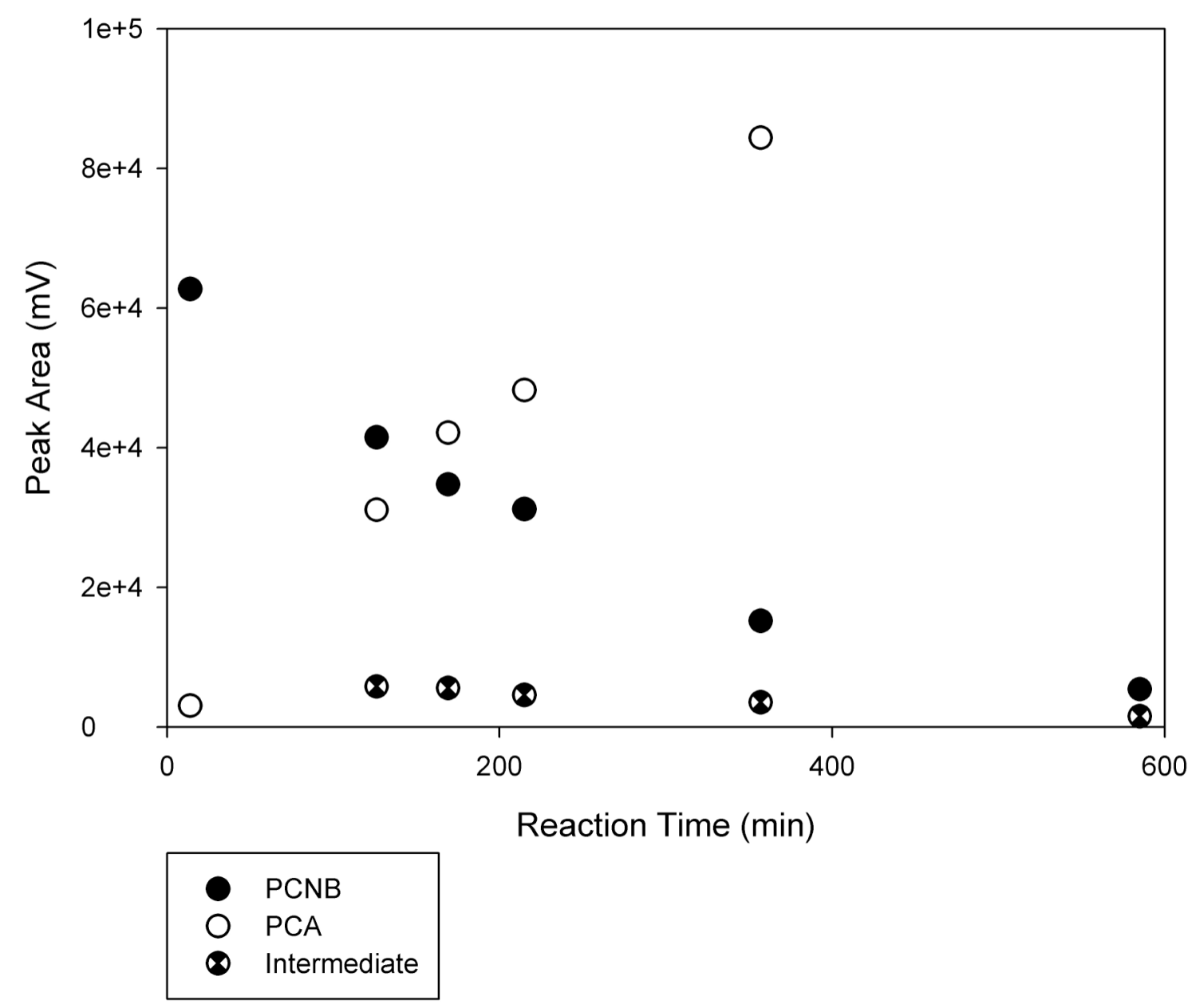

Figure S6. Plot of PCNB, PCA and intermediate chromatogram peak areas during reduction in a $0.45-\mu \mathrm{m}$-filtered $\mathrm{Fe}(\mathrm{II})$-only system at $\mathrm{pH} 7.77$ and $[\mathrm{Fe}(\mathrm{II})]=480 \mu \mathrm{M}$. Peak areas are plotted here in order to be able to show the formation and disappearance of the intermediate.

Concentrations of the intermediate cannot be calculated, as we did not possess calibration standards for use with the HPLC analyses. 